\title{
Timing and Outcome of Surgical Treatment in Supracondylar Humeral Fractures in Pediatric Patients, Khartoum, Sudan
}

Khalid Abdelsalam Tahir ( $\square$ khalidtahir777@gmail.com )

University of Khartoum https://orcid.org/0000-0002-1379-5098

Ashrf E J. Ibrahim

University of Bahri

Hassan Mohamed Hassan Elbahri

International University of Africa Faculty of Medicine

Research article

Keywords: Supracondylar humeral fracture, Delayed presentation, Gartland, Radiological outcome

Posted Date: January 2nd, 2020

DOI: https://doi.org/10.21203/rs.2.19924/v1

License: (1) (i) This work is licensed under a Creative Commons Attribution 4.0 International License.

Read Full License 


\section{Abstract}

A study aims to evaluate the timing of close surgical treatment in supracondylar humeral fractures in pediatric patients and to know the radiological outcome of its management, through measuring the mean delay per hour and assessing post-surgical radiological outcome for reduction.

A cross- sectional hospitals based study carried out in Khartoum state, through randomized cluster sampling, both data sheets and pre/post-surgical images were filled and collected. A well-constructed criteria were developed to assess the radiological outcome.

With sample size of 41 cases, we found that the mean delay from trauma to surgery was 99 hours [SE, 13], equivalent to 4.13 days. The reduction outcome criterion was significant when comparing it with the surgeon level $\mathrm{P}$ value of 0.015 , but when comparing it with the delay more than 32 hours and Gartland classification both weren't significant with $P$ values of 0.383 and 0.501 respectively.

These results are refuting the current concepts about the impossible reduction after a delay more than 32 hours and filled the current gap of knowledge about the outcome of supracondylar humeral fractures Gartland III with delayed presentation.

\section{Background}

Supracondylar Humeral fractures are the most common elbow fractures in children, and surgical fixation to those fractures is the most common operation in pediatric orthopedic Trauma. Sudan and developing countries in general have a lot of struggles which delay the presentation of this common operation, neither the international research; due to lack of cases, nor the local one; due to lack in research activities, had address outcome in these special situation.

SHF is the most common fracture in children that will need surgical management, in spite of that, time for surgery still a contra versed issue (1). There is an agreement specially with SHF type III to be an emergency, if there is vascular insufficiency for the limb, open fracture or skin puckering, evolving compartment syndrome or floating elbow, median nerve palsy, young age and if a child has cognitive disability. (2) But if there was no indication to rush to the operation room, there is a big doubt for most surgeons to do it as emergency, as shown in a survey involving 309 pediatric orthopedic surgeons in US and Canada who had been asked about their practice, $81 \%$ of them will do the operation next morning shift if there was no apparent cause for emergency. (3)

Thus, contra version didn't end in spite the risk of shifting from close to open technique and a lot of researches were done to compare starting from less than, or equal to eight hours in comparison with more than eight hours $(4,1)$, then in a comparison delay 12 hours and delay of 21 hours; all of them found no statistical difference with $P$ value of " 0.55 ", " 0.37 " and " 1.7 " respectively, which indicates the need for shifting to open technique $(4,5,6,7)$. 
In a hospital based long study with data from 1998 till 2006 with almost 190 cases after excluding all patients with emergency operation, it defined time of surgery (TS) as from injury to operation entrance, it divided the time into four quartiles to which open reduction versed close reduction operations were tested through logistic regression, it found that the probability to shift from close reduction to open reduction will increase by a factor of four after the first 15 hours post injury with statistical significant $P$ value < 0.001 , thus a close reduction becomes impossible after 32 hours. (8) This study is well controlled; the researchers did their best to control all possible factors even surgeon's interest or mood had been controlled through defined protocol to shift from close reduction to open one to which the two surgeons obligated.

Interestingly, unintended delay occurs when SHF type II is treated conservatively for a week with unsatisfactory result it will need operative reduction. A research in SHF type II did a comparison between a group which had surgery within the first seven days and another group had surgery after seven days, there was no statistical significance for the need to shift for open reduction but the mean difference was statistically significant for carrying angle degree and pin tract granuloma with $-1.5(\mathrm{Cl}-2.5$ to -0.5$)$ and $-8.9(\mathrm{Cl}-11.8$ to -5.9$)$ respectively

Addressing those fractures correctly from the start will reduce most common serious complication of it cubitus varus, which is related to the adequate reduction and fixation more than the initial trauma for which it's better to make the concern about having a good reduction rather than jeopardizing it for doing a CRPP.

The great difference in the outcome between CRPP and ORPP reported traditionally in neurological injury, elbow stiffness, ugly scaring and myositis ossifficant, had been minimized $(1,9)$. But still there is statistical significant difference between close and open reduction with lesser restriction in movement, better functional result and less time to unite with $P$ value of $0.03,0.03$ and 0.01 respectively, towards the close reduction. (10) That makes CRPP a golden stander treatment of SHF which is the goal for all surgeons dealing with it.

\section{Methods}

We design a Cross- sectional hospitals based study, we collect 41 cases through a cluster sampling to ensure an appropriate way of probability sampling technique, because Khartoum state is a large geographical area a random selection of the three cluster geographical areas where one cluster was chosen, then stratified random sampling was used to cover the three categories of hospitals and to be more precise, the private hospitals were classified in two broad groups according to the level of luxury. All stratified groups have had random selections in all of them to make a group of hospitals, which will be representative to the cluster making the result generalizable for the whole state.

All cases which fulfilled the including criteria were identified through the sentinel persons there, then data sheet was filled from both; a child caregiver and the doctor who 
performed the surgery or participated on it, and pre/post images were collected.

Through Gartland classification, all preoperative images were classified because Gartland type 4 is an intraoperative diagnosis, therefor we classified the patients as type 3, so we have only two types to consider (2 and 3).

Up to the researcher's knowledge, no criteria to score the reduction in SHF, We created criteria to classify the postoperative images and to assess the radiological outcome for the surgeries, two important factors were used; the reduction and fixation, we called it The Blue Nile Criteria.

In the first criterion to assess the reduction outcome, four factors were used; Baumann angle, anterior humeral line, translation and the tear drop profile. Total score was 7, Baumann angle (measured through Protractor application) score is 2 when an angle between 9 and 26 degrees is obtained, if the angle was more than 26 degrees or less than 9 degrees the score is zero. The score was 2 when the anterior humeral line crosses the center of capitellum, if it passes through the anterior third the score is 1, and if it passes through posterior third or anterior to the anterior third, it scored zero. As for translation, if there is no translation (both medial and lateral columns maintain the continuity) scores of 2 , if it has lateral displacement less than $5 \mathrm{~mm}$ the score is 1 , and if it has medial displacement or excessive lateral the score is zero. For tear drop profile the full score is 1 if restored and zero if not. Any case which hadn't any assessable component was excluded from the criterion, all cases got a score of 4 or more were recognized as acceptable reductions.

Second criterion to assess fixation outcome through the well know method, K- wires should hold both sides of fracture (should have a firm hold from both fragments and no wire should be intramedullary), and they should not cross at fracture side to have a score of 1 for each. It is either adequate fixation (scored 2) or inadequate fixation (scored 1 or zero).

When we joint the two above criterion, with overall score 9, we call it the Blue Nile criteria for assessing SHF, we assessed the case as acceptable radiological outcome when the score is 6 or more. Having a score of 6 was chosen based on the fact that any case to have acceptable overall outcome must have acceptable reduction, which needs a score of 4 . Fixation has a minimum consideration because any fixation would be augmented by posterior plaster of Paris slab as routine in all cases

Table (1) shown The Blue Nile Criteria 


\begin{tabular}{|c|c|c|c|c|}
\hline \multirow[t]{2}{*}{$\begin{array}{l}\text { Iumann } \\
\text { angle }\end{array}$} & $\begin{array}{c}\text { Above } 26 \text { or below } 9 \\
\text { degree }\end{array}$ & 0 & \multirow{10}{*}{$\begin{array}{l}\text { Reduction outcome } \\
\text { criterion with total } \\
\text { of } 7\end{array}$} & \multirow{14}{*}{$\begin{array}{l}\text { Overall outcome } \\
\text { criterion with total } \\
\text { score of } 9\end{array}$} \\
\hline & $\begin{array}{c}\text { Between } 9 \text { and } 26 \\
\text { degree }\end{array}$ & 2 & & \\
\hline \multirow[t]{3}{*}{$\begin{array}{l}\text { nterior } \\
\text { teral line }\end{array}$} & $\begin{array}{l}\text { Crossing posterior } \\
\text { third or anterior to } \\
\text { capitellum }\end{array}$ & 0 & & \\
\hline & $\begin{array}{l}\text { Crossing the anterior } \\
\text { third of capitellum }\end{array}$ & 1 & & \\
\hline & $\begin{array}{l}\text { Crossing the center of } \\
\text { capitellum }\end{array}$ & 2 & & \\
\hline \multirow[t]{3}{*}{ nslation } & $\begin{array}{l}\text { Medially displaced or } \\
\text { excessive lateral }\end{array}$ & 0 & & \\
\hline & $\begin{array}{l}\text { Laterally displaced } \\
\qquad(<5 \mathrm{~mm})\end{array}$ & & & \\
\hline & Not displaced & 2 & & \\
\hline \multirow{2}{*}{$\begin{array}{l}\text { ar drop } \\
\text { rofile }\end{array}$} & Not restored & 0 & & \\
\hline & Restored & 1 & & \\
\hline \multirow{2}{*}{$\begin{array}{l}\text { Two } \\
\text { gments } \\
\text { 'e fixed } \\
\end{array}$} & Yes & 1 & \multirow{4}{*}{$\begin{array}{l}\text { Fixation outcome } \\
\text { criterion total of } 2\end{array}$} & \\
\hline & No & 0 & & \\
\hline \multirow{2}{*}{$\begin{array}{l}\text { crossing } \\
\text { Iracture } \\
\text { line }\end{array}$} & $\begin{array}{l}\text { K. wires are a part } \\
\text { from each other }\end{array}$ & 1 & & \\
\hline & K. wires are crossing & 0 & & \\
\hline
\end{tabular}

\section{Results}

In a cross-sectional hospitals based study, related cases in the hospitals which had been collected through sentinel persons were 41 cases, 4 cases failed to fulfil components needed for criteria making the total number for the measuring outcome 37 cases.

A well control research done with internal validity statistical test for reliability (Cronbach's alpha) is 0.766 . The mean age for patients is 6.1 years-old [SE, 0.4] range from 2 to 13 years-old, all of them underwent CRPP, males are dominant with 71\%, most of trauma occurred at left arm with $71 \%$ and $70 \%$ that side is their dominant hand side, one 
case had associated injury which was head injury. Almost 95\% of cases presented to the health system in the first 24 hours and only 5\% had significant delay due to bone-setter.

The mean delay in hours before reaching the health facility was 4.6 hours [SE, 1.4] the maximum delay was 48.5 hours and the minimum delay was 15 minutes. $63 \%$ of patients had their first presentation to ER centre, 5\% to Primary Health Care clinic, makes a total of $68 \%$ of cases sought immediate care to health system and only $32 \%$ sought help at bone-setters.

Dreadfully the mean delay from trauma to surgery was 99 hours [SE, 13], equivalent to 4.13 days, the minimum delay was 5 hours and the maximum was 386 hours, equivalent to 16 days. Most of these delays occurred after reaching the health system with mean delay within health system of 94 hours [SE, 13.1], equivalent to 3.9 days, with maximum delay of 384 hours, table $\{2\} .71 \%$ of these delays were due to waiting for schedule list, $20 \%$ of cases had no delay and $9 \%$ of cases was due to other causes.

According to Gartland classification $46 \%$ of patients had type II SHF, and as we set 32 hours as a cut - point for CRPP, any CRPP carried out after 32 hours was considered as delayed operation, only 7 cases had their operation in the first 32 hours (17\% of cases) and the rest $83 \%$ of cases had delayed operation, table $\{3\}$. Those operations had been carried out by different levels of surgeons, $58 \%$ by orthopaedic trainees, Registrars, $15 \%$ by specialist so we can say that $63 \%$ of operations were done by Junior surgeons, $12 \%$ of operations were done by consultant orthopaedic surgeons other than paediatric speciality, and $15 \%$ of cases by paediatric orthopaedic surgeons making the percentage for operations done by senior surgeons $27 \%$.

To measure the outcome in the reduction outcome criterion from full score of 7 and acceptable score of at least 4 , the mean score was 4.5 [SE, 0.39] with minimum score of zero and maximum score of 7 and only $58 \%$ of patients ( 24 cases) had an acceptable reduction outcome, those with inacceptable reduction outcome were $32 \%$ and 4 cases were identified as missing which is only $10 \%$. The picture is gloomy in the overall outcome criterion with mean score of 5.9 [SE, 0.46]. From a full score of 9 and an acceptable score of at least 6 , the minimum score was also zero and the maximum was 9 , making those who have an acceptable overall outcome $51 \%$ of cases, with $10 \%$ missing cases who failed to fulfil the criterion and $39 \%$ of cases had inacceptable overall outcome criteria. Table $\{3\}$

Regarding the fixation, the two fragments were perfectly fixed in $54 \%$ of cases (22 cases out of 41). Failed (either not catching the two fragments or K. wire was intramedullary) in $44 \%$ and only one case wasn't assessable. Unfortunately, K. wires were crossing at fracture side in $73 \%$ of cases and only $27 \%$ had a satisfactory firm hold by $\mathrm{K}$. wires at the fracture side. 
The reduction outcome criteria had significant result when comparing it with the surgeon level (2 groups; seniors versus junior surgeons) with a Fisher's Exact Test P value of 0.015 , table $\{4\}$.With further analysis, we tested the original surgeon levels group (with 4 levels of surgeons) against the fixation outcome criteria, due to the relative small size it wasn't significant with Chi-Square Test $P$ value of 0.125 , but the data suggested a problem with fixation in consultant orthopedic surgeons group as they have adequate fixation in one quarter of cases. That rose up the query that should we test the pediatric orthopedic surgeons group against other surgeons. Interestingly, it was significant with Fisher's Exact Test $P$ value of 0.027 . Table $\{5\}$

The delay more than 32 hours and Gartland classification were both tested against reduction outcome criterion as possible confounders through Fisher's Exact and Chi-square Tests respectively; both weren't significant with $\mathrm{P}$ values of 0.383 and 0.501 , table $\{6\}$. The same picture was for the overall criteria and both variables weren't significant. Table $\{7\}$

Table (2) Descriptive analysis for different delays.

\begin{tabular}{|c|c|c|c|c|}
\hline Variables & Minimum & Maximum & \multicolumn{2}{|c|}{ Mean } \\
\cline { 4 - 5 } & & Mean & $\begin{array}{c}\text { Std. } \\
\text { Error }\end{array}$ \\
\hline $\begin{array}{c}\text { Delay before reaching health facility in } \\
\text { hours }\end{array}$ & 0.25 & 48.5 & 4.6 & 1.4 \\
\hline Delay from trauma to surgery in hours & 5 & 386 & 99 & 13 \\
\hline Delay from trauma to surgery in days & 0.21 & 16 & 4.13 & 0.5 \\
\hline Delay after reaching health facility in hours & 4.5 & 384 & 94 & 13.1 \\
\hline Delay after reaching health facility in days & 0.19 & 16 & 3.92 & 0.5 \\
\hline
\end{tabular}

Table (3) Frequencies analysis for different categorical data 


\begin{tabular}{|c|c|c|c|}
\hline \multirow{2}{*}{ Variables } & Frequency & Percent \\
\hline Gartland Classification & Type II & 19 & $46 \%$ \\
\cline { 2 - 4 } & Type III & 22 & $54 \%$ \\
\hline Delay more than 32 hours & No delay & 7 & $17 \%$ \\
\cline { 2 - 4 } & Delayed & 34 & $83 \%$ \\
\hline Reduction criteria & Inacceptable reduction & 13 & $32 \%$ \\
\cline { 2 - 4 } & Acceptable reduction & 24 & $58 \%$ \\
\cline { 2 - 4 } & Total & 37 & $90 \%$ \\
\cline { 2 - 4 } & Missing & 4 & $10 \%$ \\
\hline Overall criteria & Inacceptable & 16 & $39 \%$ \\
\cline { 2 - 4 } & Acceptable & 21 & $51 \%$ \\
\cline { 2 - 4 } & Total & 37 & $90 \%$ \\
\cline { 2 - 4 } & Missing & 4 & $10 \%$ \\
\cline { 2 - 4 } & & & \\
\hline
\end{tabular}

Table (4) Test between reduction outcome criteria and surgeon level.

\begin{tabular}{|c|c|c|c|c|}
\hline & \multicolumn{2}{|c|}{ Surgeon level } & \multirow{2}{*}{ Total } \\
\hline & & $\begin{array}{c}\text { Senior } \\
\text { Surgeons }\end{array}$ & $\begin{array}{c}\text { Junior } \\
\text { surgeons }\end{array}$ & \\
\hline \multirow{2}{*}{$\begin{array}{l}\text { Reduction outcome } \\
\text { criteria }\end{array}$} & $\begin{array}{l}\text { Not acceptable } \\
\text { reduction }\end{array}$ & 0 & 13 & 13 \\
\hline & Acceptable reduction & 9 & 15 & 24 \\
\hline \multicolumn{2}{|c|}{$\frac{1}{\text { Total }}$} & 9 & 28 & 37 \\
\hline
\end{tabular}

Fisher's Exact Test, P value is 0.015 (significant)

Table (5) Tests between overall outcome criteria and surgeon level (Paediatric orthopaedic surgeon versus other surgeons). 


\begin{tabular}{|c|c|c|c|c|}
\hline \multicolumn{2}{|c|}{} & \multicolumn{2}{|c|}{ Surgeon level } & Total \\
\cline { 3 - 4 } \multicolumn{2}{|c|}{} & $\begin{array}{c}\text { Pediatric orthopedic } \\
\text { Surgeons }\end{array}$ & $\begin{array}{c}\text { Other } \\
\text { surgeons }\end{array}$ & \\
\hline $\begin{array}{c}\text { Overall outcome } \\
\text { criteria }\end{array}$ & $\begin{array}{c}\text { Not } \\
\text { acceptable }\end{array}$ & 0 & 16 & 16 \\
\cline { 2 - 5 } & Acceptable & 6 & 15 & 21 \\
\hline \multicolumn{2}{|c|}{ Total } & 6 & 31 & 37 \\
\hline
\end{tabular}

Fisher's Exact Test, $\mathrm{P}$ value is 0.027 (significant)

Table (6) Tests between reduction outcome criteria and different variables.

\begin{tabular}{|c|c|c|c|c|}
\hline & \multicolumn{2}{|c|}{ Reduction outcome criteria } & \multirow[t]{2}{*}{ Tota } \\
\hline & & $\begin{array}{l}\text { Not acceptable } \\
\text { reduction }\end{array}$ & $\begin{array}{c}\text { Acceptable } \\
\text { reduction }\end{array}$ & \\
\hline \multirow{2}{*}{$\begin{array}{c}\text { Causes of delay before arriving health } \\
\text { system }\end{array}$} & No delay & 11 & 24 & 35 \\
\hline & $\begin{array}{l}\text { Bone- } \\
\text { setter }\end{array}$ & 2 & 0 & 2 \\
\hline \multicolumn{2}{|l|}{ Total } & 13 & 24 & 37 \\
\hline \multirow{2}{*}{ Delay more than 32 hours } & No delay & 1 & 6 & 7 \\
\hline & Delayed & 12 & 18 & 30 \\
\hline \multicolumn{2}{|l|}{ Total } & 13 & 24 & 37 \\
\hline \multirow{2}{*}{ Gartland classification } & Type II & 5 & 12 & 17 \\
\hline & Type III & 8 & 12 & 20 \\
\hline \multicolumn{2}{|l|}{ Total } & 13 & 24 & 37 \\
\hline
\end{tabular}

Fisher's Exact Test for Causes of delay before arriving health system, $\mathrm{P}$ value is 0.117 (insignificant)

Fisher's Exact Test for Delay more than 32 hours, P value is 0.383 (insignificant)

Pearson Chi-Square for Gartland classification, $\mathrm{P}$ value is 0.501 (insignificant)

Table (7) Tests between overall outcome criteria and different variables. 


\begin{tabular}{|c|c|c|c|c|}
\hline & & \multicolumn{2}{|c|}{ Overall outcome criteria } & \multirow[t]{2}{*}{ Tota } \\
\hline & & Not acceptable & Acceptable & \\
\hline \multirow[t]{2}{*}{ Causes of delay before arriving health system } & No delay & 14 & 21 & 35 \\
\hline & Bone-setter & 2 & 0 & 2 \\
\hline \multicolumn{2}{|l|}{ Total } & 16 & 21 & 37 \\
\hline \multirow[t]{2}{*}{ Delay more than 32 hours } & No delay & 2 & 5 & 7 \\
\hline & Delayed & 14 & 16 & 30 \\
\hline \multicolumn{2}{|l|}{ Total } & 16 & 21 & 37 \\
\hline \multirow[t]{2}{*}{ Gartland classification } & Type II & 5 & 12 & 17 \\
\hline & Type III & 11 & 9 & 20 \\
\hline \multicolumn{2}{|l|}{ Total } & 16 & 21 & 37 \\
\hline
\end{tabular}

Fisher's Exact Test for Causes of delay before arriving health system, $\mathrm{P}$ value is 0.180 (insignificant)

Fisher's Exact Test for Delay more than 32 hours, $\mathrm{P}$ value is 0.674 (insignificant) Pearson Chi-Square for Gartland classification, $\mathrm{P}$ value is 0.117 (insignificant)

\section{Discussion}

The research was intended to address the gap in knowledge in regard to SHF in paediatric patients in Khartoum, Sudan. For that a cross sectional study was designed to study closed management of SHF and to know the outcome of it and to facilitate generation of hypothesis for further researches

The mean delay from trauma to surgery was 99 hours [SE, 13], with maximum delay of 386 hours, this too huge as most of literatures talking about 8 hours and 21 hours' delay as cut between CRPP and ORPP, and some authors put a delay more than 32 hours as cut point for CRPP (8). With a concept of dealing with SHF as an urgent operation if it was not an emergency but never as an elective operation. $(1,7)$ Although no study gave an exact figure for delay with CRPP; our 4 days' delay is a long delay and it is close to study for CRPP after 7 days done for patients with acceptable Gartland type II SHF failed in conservative management which implies a minimum reduction defect unlike our research which had more patients with Gartland type III (11)

Based on literatures, shift from close reduction to open reduction will increase by a factor of 4 after the first 15 hours post injury with statistical significant $P$ value $<0.001$, thus CRPP became impossible after 32 hours. (7) we grouped our sample in two groups those who had surgery before 32 hours (no delay group) consisting $17 \%$ of the cases, and those after 32 hours (delay group) consisting $83 \%$ (majority). We 
failed to find a statistical significance when comparing those groups with reduction or overall outcome criteria, table $\{6,7\}$. Maximum delay 386 hours (16 days) with an acceptable closed reduction and overall outcome criteria occurs in 8 years-old female with SHF Gartland II operated by orthopaedic trainee, also in SHF Gartland III an acceptable CRPP for both criteria achieved with maximum delay of 111 hours, 4.6 days, occurred in 4-year-old boy operated also by orthopaedic trainee, and all surgeon levels had operations at delayed group, with the acceptable reduction outcome criterion in more than half of cases delay group through CRPP, and perfect full score in $39 \%$ of them, those results refute the current hypothesis about impossible reduction after 32 hours.

Going through the data after refuting the delay more than 32 hours as a cause for inacceptable reduction outcome criterion table $\{6\}$, the effect of different surgeon levels was very clear. We found a significant result comparing senior versus junior surgeons, with a Fisher's Exact Test $P$ value of 0.015 , table $\{4\}$. We didn't find a supporting paper for that finding and in contrast junior surgeons found not to have inferior performance to consultants in a research, (12) making this result special for our situation and alarming about the learning curve in our training program.

When adding the fixation factor only paediatric orthopaedic surgeons had acceptable overall outcome criterion with significant result Fisher's Exact Test $P$ value of 0.027 . Table $\{5\}$ this finding may not be that import as mentioned before, because all patients will have above elbow cast.

\section{Conclusion}

In a cross sectional hospitals based study aims to study the timing of close surgical treatment in SHF in pediatric patients and to know the radiological outcome of its management, through measuring the mean delay per hour and identifying the causes. And assessing post-surgical radiological outcome for reduction.

We found that the mean delay from trauma to surgery was 99 hours [SE, 13], equivalent to 4.13 days, $71 \%$ of these delay was due to wait for schedule list within the health system. The reduction outcome criterion was significant when comparing it with the surgeon level $P$ value of 0.015 , but when comparing it with the delay more than 32 hours and Gartland classification both weren't significant with $P$ values of 0.383 and 0.501 respectively.

\section{Table Of Abbreviations}




\begin{tabular}{|l|l|}
\hline AHL & Anterior humeral line \\
\hline CRPP & Close reduction and percutaneous pining \\
\hline K. wires & Kirschner wires \\
\hline ORPP & Open reduction and percutaneous pining \\
\hline PCCF & Pediatric Comprehensive Classification of Long-Bone Fractures \\
\hline SHHS-2 & Sudan's household survey round two \\
\hline SHF & Supracondylar humeral fracture \\
\hline
\end{tabular}

\section{Declarations}

\section{Ethical approval}

Had been taken from Sudan Medical Specialization board. Ethical committee, and file had been attached as supplementary material (Ethical clearance) show an image from the committee approval.

\section{Consent for publication}

Not applicable

\section{Availability of Data and Material}

Data had been collected through data sheet and then enter in SPSS program. A form from the data sheet and the hole original data which had been enter to the SPSS had been attached as supplementary material

\section{Competing interests}

No competing of interest as this article is a part of my partial commitment to have the clinical MD, in Trauma and Orthopedic Surgery, Me (Corresponding Author) was a trainee and the other authors are my supervisors to do the research.

\section{Funding}

The research is self-funding by the corresponding author, not that huge fund needed for it.

\section{Authors contributions}

All authors were part in all steps from the title till this manuscript. 


\section{AKNOWLEGMENT}

I would like to thank all those who had worked as sentinel's person for detecting the cases; registrars, doctors and operation rooms scrub nurses.

I sincerely would like to thank my friends who helped me in statistical analysis; Ms. Emitnan Khalid and Dr. Emmanoil Talous. And special thanks to my friend Mr. Mohand Malik (an English expertise), who helped a lot.

\section{References}

1. John M. (Jack) Flynn, David L. Skaggs, Peter M. Waters. Rockwood and Wilkins' Fractures in Children. 8th ed. USA. Library of Congress Cataloging-in-Publication. 2015. p. 850

2. Joshua M. Abzug, Martin J. Herman. Management of Supracondylar Humerus Fractures in Children: Current Concepts. J Am Acad Orthop Surg 2012;20: 69-77.

3. Craig T. Carter, Styles L. Bertrand, David M. Cearley, Management of Pediatric Type III Supracondylar Humerus Fractures in the United States: Results of a National Survey of Pediatric Orthopaedic Surgeons. J Pediatr Orthop 2013. 33:750-754

4. yengar, Shuba R, Hoffinger, Scott A,Townsend, Donald R. Early Versus Delayed Reduction and Pinning of Type III Displaced Supracondylar Fractures of the Humerus in Children: A Comparative Study. J Orthop Trauma. 1999. 13(1):51-55.

5. Neeraj Gupta, Robert M. Kay, Kellie Leitch, J. Dominic Femino,Vernon T. Tolo, David L. Skaggs. Effect of Surgical Delay on Perioperative Complications and Need for Open Reduction in Supracondylar Humerus Fractures in Children. J Pediatr Orthop. 2004. 24:245-248

6. John M. Kronner Jr, Julie E. Legakis, Natalia Kovacevic, Ronald L. Thomas, Richard A. K. Reynolds, Eric T. Jones. An evaluation of supracondylar humerus fractures: is there a correlation between postponing treatment and the need for open surgical intervention?. J Child Orthop. 2013. 7:131-137.

7. Bales JG, Spencer HT, Wong MA, et al. The Effects of Surgical Delay on the Outcome of Pediatric Supracondylar Humeral Fractures. J Pediatr Orthop. 2010. 30:785-791

8. Ahmet Ozgur Yildirim, Vuslat Sema Unal, Ozdamar Fuad Oken, Murat Gulcek, Metin Ozsular, Ahmet Ucaner. Timing of surgical treatment for type III supracondylar humerus fractures in pediatric patients. J Child Orthop (2009) 3:265-26.

9. Charles T. Mehlman, William M. Strub, Dennis R. Roy, Eric J. Wall, Alvin H. Crawford. The Effect of Surgical Timing on the Perioperative Complications of Treatment of Supracondylar Humeral Fractures in Children. JBJS. 2001. 83-A, 3.

10. Cem Nuri Aktekin, Ali Toprak, Akif Muhtar Ozturk, Murat Altay, Bulent Ozkurt, Abdullah Yalcin Tabak. Open reduction via posterior triceps sparing approach in comparison with closed treatment of posteromedial displaced Gartland type III supracondylar humerus fractures. J Pediatr Orthop. 2008. 17:171-178. 
11. Silva M, Wong TC, Bernthal NM. Outcomes of Reduction More Than 7 Days After Injury in Supracondylar Humeral Fractures in Children. J Pediatr Orthop. 2011. 31:751-756.

12. Noora Tuomilehto, Reetta Kivisaari, Antti Sommarhem, Aarno Y Nietosvaara. Outcome after pin fixation of supracondylar humerus fractures in children: postoperative radiographic examinations are unnecessary. ISSN: 1745-3674 (Print) 1745-3682 (Online) Journal homepage: http://www.tandfonline.com/loi/iort20

\section{Supplementary Files}

This is a list of supplementary files associated with this preprint. Click to download.

- analysis.sav 